Journal of Pharmaceutical Science and Clinical Research, 2019, 01, 29-38

DOI: $10.20961 /$ jpscr.v4i1.26544

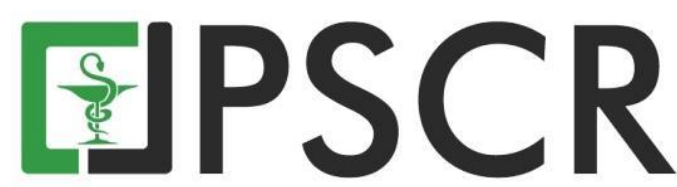

\title{
Uji Aktivitas Antibakteri Ekstrak Dan Getah Pelepah Serta Bonggol Pisang Kepok Kuning (Musa paradisiaca Linn.) Terhadap Bakteri Pseudomonas aeruginosa dan Klebsiella pneumoniae Dengan Metode Difusi Agar
}

\author{
Rumaisya Azizah dan Anif Nur Artanti* \\ Program Studi D3 Farmasi, Fakultas Matematika dan Ilmu Pengetahuan Alam Universitas Sebelas Maret \\ *email korespondensi : anif.apt@staff.uns.ac.id
}

\begin{abstract}
Abstrak : Tanaman pisang kepok kuning (Musa paradisiaca Linn.) dilaporkan memiliki aktivitas antibakteri karena mengandung senyawa saponin, flavonoid dan alkaloid. Ekstrak pelepah dan bonggol pisang kepok kuning terbukti mampu menghambat pertumbuhan $S$. aureus dan E. coli. Tujuan dari penelitian ini adalah untuk melihat potensi antibakteri ekstrak dan getah pelepah serta bonggol pisang kepok kuning terhadap pertumbuhan bakteri Pseudomonas aeruginosa ATCC 27853 dan Klebsiella pneumoniae ATCC 13883. Ekstraksi dilakukan dengan metode maserasi menggunakan pelarut etanol $96 \%$ sedangkan getah pisang diperoleh dengan cara pemarutan dan penyaringan pelepah tanaman pisang. Uji aktivitas antibakteri terhadap ekstrak dan getah dari pelepah dan bonggol pisang dilakukan dengan metode difusi. Daya aktivitas antibakteri diperoleh dengan mengukur diameter zona hambat setelah pemberian 6 variasi konsentrasi sampel ekstrak dan getah. Kontrol positif menggunakan amoxicillin $25 \mu \mathrm{g} /$ disk dan kontrol negatif menggunakan aquadest. Hasil penelitian menunjukkan ekstrak dan getah pelepah serta bonggol pisang kepok kuning memiliki aktivitas antibakteri. Diameter daya hambat paling besar terhadap Pseudomonas aeruginosa dihasilkan oleh ekstrak bonggol dengan kategori kuat $(10,57 \mathrm{~mm} \pm 0,35)$ sedangkan pada Klebsiella pneumoniae dihasilkan oleh ekstrak pelepah dengan kategori sedang $(8,62 \mathrm{~mm} \pm$ $0,45)$.
\end{abstract}

Kata Kunci : Pisang; Antibakteri; Pseudomonas aeruginosa; Klebsiella pneumoniae

Abstract. Antibacterial Activity of Extract and Saps from Midrib and Stem's Musa paradiaca Linn. against Pseudomonas aeruginosa and Klebsiella pneumoniae Bacteria using Agar Diffusion Method. The plant of Musa paradisiaca Linn. was used to antibacterial because it contains saponin, flavonoid and alkaloid compounds. The extract of midrib and stem of Musa paradisiaca Linn was reported can inhibiting the growth of $S$. aureus and E. coli. The aim of this study is to measure the antibacterial activity of extract and sap from midrib and stem of Musa paradisiaca Linn against Pseudomonas aeruginosa ATCC 27853 and Klebsiella pneumoniae ATCC 13883. The extracts were prepared by maceration method using $96 \%$ ethanol solvent and the sap was made by filtration process. The strength of antibacterial activity was obtained by measuring the inhibition zone diameter by 6 variations of concentration. Positive control was used amoxicillin $25 \mu \mathrm{g} /$ disk and aquadest as negative control. The results showed extract and sap of midrib and stem have antibacterial activity. The largest inhibitory diameter of Pseudomonas aeruginosa was obtained from stem extracts with strong category $(10.57 \mathrm{~mm} \pm 0.35)$ whereas Klebsiella pneumoniae was obtained from midrib extracts with medium category $(8.62 \mathrm{~mm} \pm$ $0.45)$. 
Keywords: Banana; Antibacterial; Pseudomonas aeruginosa; Klebsiella pneumoniae

\section{Pendahuluan}

Pseudomonas aeruginosa merupakan bakteri patogen oportunistik pada manusia, dapat memasuki daerah dengan sistem pertahanan yang tidak normal, misalnya saat membran mukosa dan kulit terbuka karena luka (Mayasari, 2005). Klebsiella pneumonia merupakan bakteri Gramnegatif berbentuk batang yang dapat menyebabkan infeksi pada saluran pernafasan seperti pneumonia (Jawetz et al., 2005). Kedua bakteri tersebut merupakan bakteri penyebab infeksi saluran pernafasan akut. Menurut Tarina dan Sri (2017), secara historis Klebsiella pneumoniae digambarkan sebagai agen Friedlander's pneumoniae penyebab pnemonia. Penelitian oleh Lubis et al., (2016a) melaporkan angka kejadian pasien yang terdiagnosa infeksi pernafasan bawah di RSUP M. Lubis et al. (2016b) mencapai 56,25\% dan diantaranya disebabkan oleh Klebsiella pneumoniae, sedangkan 12,50\% lainya disebabkan oleh Pseudomonas aeruginosa. Pseudomonas aeruginosa juga dilaporkan menjadi penyebab infeksi pada bayi baru lahir sebesar 13,68\% dari seluruh kelahiran hidup dengan angka kematian 14,18\% pada tahun 2005 di Rumah Sakit Cipto Mangunkusumo (Aminullah, 2005).

Penanganan infeksi dapat diobati dengan penggunaan antibiotika yang rasional, tepat dan aman. Namun terjadi kenaikan angka infeksi yang diakibatkan karena bakteri yang telah resisten terhadap antibiotik. Menurut Rukmono dan Reni (2013), bakteri Gram negatif yang menjadi perhatian dalam beberapa tahun terakhir diantaranya adalah Klebsiella pneumoniae dan Pseudomonas aeruginosa. Bakteri tersebut telah banyak mengalami multidrug resisten (MDR). Oleh karena itu, perlu dilakukan pencegahan dalam upaya penanggulangan penyakit infeksi, salah satunya dengan memanfaatkan bahan alam yaitu menggunakan bonggol dan pelepah pisang.

Pelepah pisang mengandung senyawa saponin, steroid, triterpenoid, alkaloid dan tannin (Wibowo dan Erna, 2015). Aktivitas antibakteri sebelumnya dilaporkan Ningsih et al., (2013) bahwa bagian tanaman pisang kepok kuning yang diuji dengan bakteri Staphylococcus aureus dan Escherichia coli menunjukkan kemampuannya dalam menghambat pertumbuhan bakteri. Penelittian ini berfokus pada kemampuan dari bonggol dan pelepah pisang kepok kuning dalam meghambat pertumbuhan Pseudomonas aeruginosa dan Klebsiella baik dalam bentuk ekstrak maupun getahnya serta identifikasi kandungan kimia pada kedua bagian tersebut. 


\section{Bahan dan Metode}

\subsection{Bahan}

Kultur bakteri Pseudomonas aeruginosa ATCC 27853 dan Klebsiella pneumoniae ATCC 13883 yang diperoleh dari Laboratorium Mikrobiologi Fakultas Kedokteran UNS. Alat-alat gelas, bejana maserasi, hot plate, waterbath, termometer, vacum rotary evaporator, tabung reaksi (Herma), cawan petri, jarum ose, pinset, mikropipet (Onemed), yellow tip, autoklaf, Laminar Air Flow (Biobase), incubator, neraca analitik (Precisa), jangka sorong (Krisbow), Moisture Analyzer (Ohaus MB23), bunsen, cawan porselin, gelas kaca, dan bahan yang digunakan antara lain alumunium foil, kain flanel, kain saring, aquades steril, spiritus, cakram disk (Oxioid), amoxicillin 25 $\mu \mathrm{g} /$ disk (Oxioid), media Mueller-Hinton Agar (MHA), media Nutrient Agar (Merck), larutan $\mathrm{NaCl}$ konsentrasi 0,9\% steril, standar Mac Farland 0,5 , plat silika gel 60 F 254 (Merck), etanol 96\% (Merck), butanol (Merck), asam asetat (Merck,).

\subsection{Metode}

\subsubsection{Preparasi sampel}

Ekstrak bonggol dan pelepah pisang diperoleh dengan cara maserasi menggunakan pelarut etanol 96\%. Ekstraksi dilakukan dengan metode maserasi selama 24 jam, kemudian dilakukan remaserasi selama 24 jam. Sampel pelepah diperoleh dengan cara melakukan pemarutan pelepah pisang, kemudian getah yang dihasilkan disaring menggunakan kertas saring.

\subsubsection{Identifikasi kandungan kimia}

Ekstrak dan getah pelepah serta bonggol selanjutnya dilakukan pemeriksaan kandungan metabolit sekunder saponin, flavonoid dan alkaloid. Pemeriksaan saponin dilakukan secara kualitatif menggunakan uji tabung dan dikocok selama 10 menit menggunakan akuades. Pengamatan dilakukan apabila terbentuk busa saat ditetesi dengan HCL 2 N, jika busa tidak hilang maka diidentifikasi menunjukkan adanya saponin. Pemeriksaan flavonoid dan alkaloid dilakukan dengan metode KLT, sampel ditotolkan pada lempeng KLT Silika GF$_{254}$ dengan menggunakan senyawa pembanding quinine (alkaloid) dan quercetin (flavonoid). Lempeng KLT kemudian dielusi dengan fase gerak larutan butanol: asam asetat : air (4:1:5) v/v. Pengamatan spot KLT dilakukan dibawah lampu UV $254 \mathrm{~nm}$ dan $366 \mathrm{~nm}$.

\subsubsection{Pengujian aktivitas antibakteri}

Menyiapkan kultur Pseudomonas aeruginosa dan Klebsiella pneumoniae yang sudah disamakan kekeruhannya dengan standar Mc Farland 0,5. Suspensi bakteri uji kemudian diratakan pada media Mueller Hinton Agar (MHA) menggunakan metode spread plate. Kemudian 
cakram disk yang berisi sampel dengan konsentrasi yang telah ditentukan dimasukkan di media Mueller Hinton Agar (MHA) berikut dengan kontrol positif yaitu amoxicillin $25 \mu \mathrm{g} / \mathrm{disk}$ dan kontrol negatif berupa aquadest steril. Konsentrasi sampel yang digunakan yaitu $200 \mathrm{mg} / \mathrm{mL}, 250$ $\mathrm{mg} / \mathrm{mL}, 300 \mathrm{mg} / \mathrm{mL}, 350 \mathrm{mg} / \mathrm{mL}, 400 \mathrm{mg} / \mathrm{mL}$ and $450 \mathrm{mg} / \mathrm{mL}$. Selanjutnya media yang sudah dipreparasi kemudian diinkubasi pada suhu $37^{\circ} \mathrm{C}$ selama 24 jam. Uji aktivitas antibakteri dilakukan dengan mengukur nilai Diameter Daerah Hambat (DDH) mengunakan jangka sorong digital. Zona bening yang terbentuk mengindikasikan daya antibakteri larutan uji terhadap bakteri Pseudomonas aeruginosa dan Klebsiella pneumonia.

\section{Hasil dan Pembahasan}

Identifikasi senyawa dilakukan untuk mengetahui kandungan metabolit sekunder yang terkandung dalam ekstrak serta getah pelepah dan bonggol pisang kepok kuning secara kualitatif yaitu ada tidaknya kandungan senyawa, sehingga dapat diketahui metabolit sekunder yang berpotensi sebagai antibakteri. Hasil identifikasi senyawa sampel uji pisang kepok kuning dapat dilihat pada Tabel 1 .

Tabel 1. Hasil Identifikasi Senyawa Metabolit Sekunder pada ekstrak bonggol pisang dan ekstrak pelepah pisang, getah bonggol pisang dan getah pelepah pisang. Tanda positif (+) menunjukkan bahwa sampel uji mengandung metabolit sekunder dan tanda negativf (-) menunjukkan sampel uji tidak mengandung metabolit sekunder

\begin{tabular}{ccccc}
\hline No. & \multicolumn{1}{c}{ Sampel } & Saponin & $\begin{array}{c}\text { Alkaloid } \\
\text { (Quinine) }\end{array}$ & $\begin{array}{c}\text { Flavonoid } \\
\text { (Quercetin) }\end{array}$ \\
\hline 1 & Ekstrak Bonggol & + & + & - \\
2 & Ekstrak Pelepah & + & - & - \\
3 & Getah Bonggol & + & - & - \\
4 & Getah Pelepah & + & - & - \\
\hline
\end{tabular}

Hasil uji saponin menunjukkan bahwa semua sampel positif mengandung saponin. Hasil positif saponin ditandai dengan busa konstan yang tidak hilang apabila ditetesi HCL 2 N. Menurut Ngajow et al.,(2013) saponin bekerja sebagai antibakteri dengan berdifusi melalui membran luar dan dinding sel yang rentan, kemudian mengikat sitoplasma dan mengganggu serta mengurangi kestabilan sitoplasma hingga mengakibatkan kematian sel. Saponin memiliki glikosil yang berfungsi sebagai gugus polar dan gugus steroid dan triterpenoid sebagai gugus nonpolar. Senyawa yang memiliki gugus polar dan nonpolar bersifat aktif permukaan sehingga saat dikocok dengan air saponin dapat membentuk misel. Pada struktur misel gugus polar menghadap ke luar sedangkan gugus nonpolarnya menghadap ke dalam. Keadaan inilah yang tampak seperti busa, karena itu dalam analisis ini dilihat kemampuan sampel dalam membentuk busa (Sangi et al., 2008). 
Hasil uji flavonoid yang dilakukan dengan metode Kromatografi Lapis Tipis (KLT) menggunakan standar quercetin menunjukkan bahwa sampel ekstrak maupun getah tidak mengandung senyawa flavonoid quercetin. Hal ini ditunjukkan dengan tidak adanya nilai Rf pada plat KLT yang sama dengan nilai Rf standar. Hasil analisis KLT ditunjukkan pada Gambar 1.

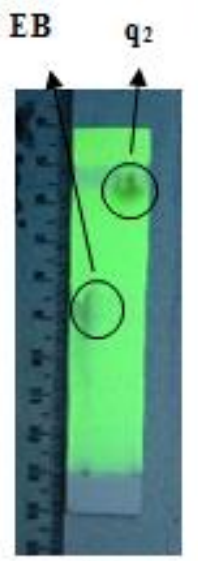

(a)

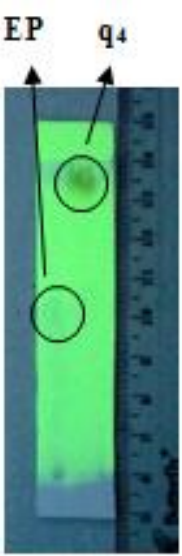

(b)

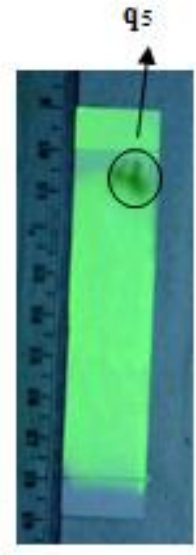

(c)

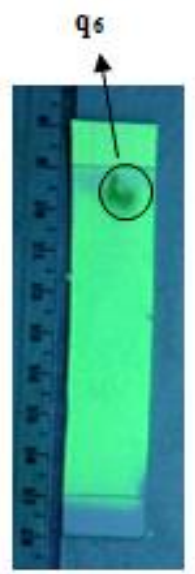

(d)

Gambar 1. Profil KLT identifikasi golongan flavonoid dengan fase diam plat KLT silika gel 60 F254 dan fase gerak butanol : asam asetat : air (4:1:5) pada sinar UV $254 \mathrm{mn}$. Hasil KLT standar quercetin (q) EB : Ekstrak bonggol (a), EP : ekstrak pelepah (b), GB : getah bonggol (c) dan GP : getah pelepah (d) pisang kepok kuning

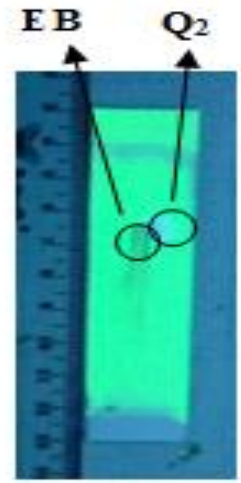

(a)

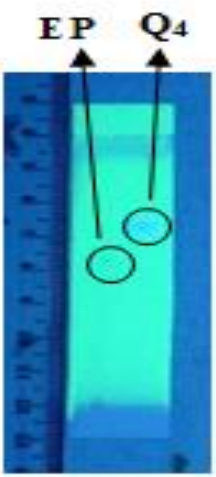

(b)

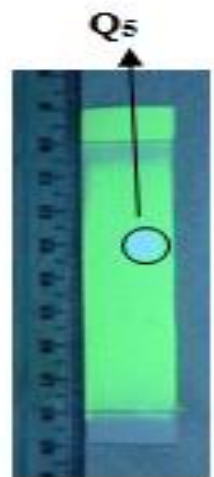

(c)

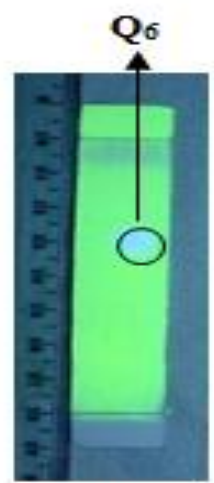

(d)

Gambar 2. Profil KLT identifikasi golongan alkaloid dengan fase diam plat KLT silika gel 60 F254 dan fase gerak butanol : asam asetat : air (4:1:5) pada sinar UV $254 \mathrm{mn}$. Hasil KLT standar quinine (q) EB : Ekstrak bonggol (a), EP : ekstrak pelepah (b), GB : getah bonggol (c) dan GP : getah pelepah (d) pisang kepok kuning

Pada uji senyawa golongan alkaloid dengan standar quinine diketahui pada ekstrak bonggol positif, sedangkan pada ekstrak pelepah negatif. Alkaloid memiliki kemampuan sebagai antibakteri. Menurut Devi dan Tuty (2017), alkaloid memiliki senyawa yang dapat mengganggu komponen penyusun peptidoglikan pada sel bakteri sehingga lapisan dinding sel tidak terbentuk 
secara utuh dan menyebabkan kematian sel bakteri tersebut. Hasil analisis KLT ditunjukkan pada Gambar 2. Metode KLT memberikan fleksibilitas yang lebih besar dalam hal fase gerak, memiliki berbagai macam teknik untuk optimasi pemisahan, serta lebih mudah untuk mengubah atau menambah eluen agar sensitiv dan selektiv Komponen kimia dalam sampel bergerak naik mengikuti fase gerak karena daya serap adsorben terhadap komponen kimia tidak sama sehingga komponen kimia dapat bergerak dengan jarak yang berbeda berdasarkan tingkat kepolarannya. Hal inilah yang menyebabkan terjadinya pemisahan komponen kimia di dalam sampel (Alen et al, 2017).

Tabel 2. Hasil Uji Antibakteri terhadap Pseudomonas aeruginosae pengukuran rata-rata Diameter Daya Hambat (DDH) pada ekstrak bonggol, ekstrak pelepah, getah bonggol dan getah pelepah pisang.

\begin{tabular}{|c|c|c|c|c|c|}
\hline \multirow[t]{2}{*}{ Kode } & \multirow[t]{2}{*}{ Sampel } & \multicolumn{4}{|c|}{ Diameter Daya Hambat (mm) } \\
\hline & & $\begin{array}{l}\text { Ekstrak } \\
\text { Bonggol }\end{array}$ & $\begin{array}{l}\text { Ekstrak } \\
\text { Pelepah }\end{array}$ & $\begin{array}{l}\text { Getah } \\
\text { Bonggol }\end{array}$ & $\begin{array}{l}\text { Getah } \\
\text { Pelepah }\end{array}$ \\
\hline 1 & $200 \mathrm{mg} / \mathrm{mL}$ & $7,01 \pm 0,31$ & $7,69 \pm 0,06$ & $7,28 \pm 0,18$ & $0,00 \pm 0,00$ \\
\hline 2 & $250 \mathrm{mg} / \mathrm{mL}$ & $7,21 \pm 0,11$ & $7,73 \pm 0,11$ & $7,58 \pm 0,42$ & $6,95 \pm 0,12$ \\
\hline 3 & $300 \mathrm{mg} / \mathrm{mL}$ & $7,37 \pm 0,25$ & $8,04 \pm 0,27$ & $7,65 \pm 0,12$ & $7,01 \pm 0,30$ \\
\hline 4 & $350 \mathrm{mg} / \mathrm{mL}$ & $7,80 \pm 0,22$ & $8,19 \pm 0,23$ & $7,73 \pm 0,11$ & $7,06 \pm 0,11$ \\
\hline 5 & $400 \mathrm{mg} / \mathrm{mL}$ & $7,91 \pm 0,10$ & $8,60 \pm 0,25$ & $7,77 \pm 0,19$ & $7,22 \pm 0,09$ \\
\hline 6 & $450 \mathrm{mg} / \mathrm{mL}$ & $8,10 \pm 0,45$ & $8,62 \pm 0,45$ & $7,91 \pm 0,02$ & $7,27 \pm 0,04$ \\
\hline $\mathrm{P}$ & $\begin{array}{l}\text { Kontrol } \\
\text { (Amoxicillin } \\
\mu \mathrm{g} / \text { disk) }\end{array}$ & \multicolumn{4}{|c|}{$7,22 \pm 0,14$} \\
\hline $\mathrm{N}$ & $\begin{array}{l}\text { Kontrol Negatif } \\
\text { (aquadest steril) }\end{array}$ & \multicolumn{4}{|c|}{0,00} \\
\hline
\end{tabular}

Pengujian aktivitas antibakteri pada ekstrak dan getah pelepah serta bonggol pisang kepok kuning dilakukan dengan metode disk diffusion. Prinsip dari pengujian adalah terbentuknya area jernih yang mengindikasikan adanya hambatan pertumbuhan mikroorganisme oleh sampel pada permukaan media yang ditanami bakteri setelah diinkubasi selama 24 jam pada suhu $37^{\circ} \mathrm{C}$, sehingga besarnya daya hambat dapat diketahui dengan jelas. Pemilihan metode disk diffusion 
karena terdapat beberapa kelebihan yaitu dalam pelaksanaannya lebih mudah dan praktis, sebab tidak memerlukan peralatan khusus, cocok dengan sampel bentuk ekstrak cair sebab terdapat proses penjenuhan sampel di dalam cakram disk sehingga zona hambat yang terbentuk lebih mudah dilakukan pengukuran.

Tabel 3. Hasil Uji Antibakteri terhadap Klebsiella pneumoniae pengukuran rata-rata Diameter Daya Hambat (DDH) pada ekstrak bonggol, ekstrak pelepah, getah bonggol dan getah pelepah pisang.

\begin{tabular}{|c|c|c|c|c|c|}
\hline \multirow[t]{2}{*}{ Kode } & \multirow[t]{2}{*}{ Sampel } & \multicolumn{4}{|c|}{ Diameter Daya Hambat (mm) } \\
\hline & & $\begin{array}{l}\text { Ekstrak } \\
\text { Bonggol }\end{array}$ & $\begin{array}{l}\text { Ekstrak } \\
\text { Pelepah }\end{array}$ & $\begin{array}{l}\text { Getah } \\
\text { Bonggol }\end{array}$ & $\begin{array}{l}\text { Getah } \\
\text { Pelepah }\end{array}$ \\
\hline 1 & $200 \mathrm{mg} / \mathrm{mL}$ & $7,79 \pm 0,27$ & $6,74 \pm 0,09$ & $0,00 \pm 0,00$ & $0,00 \pm 0,00$ \\
\hline 2 & $250 \mathrm{mg} / \mathrm{mL}$ & $8,61 \pm 0,26$ & $6,77 \pm 0,10$ & $6,60 \pm 0,06$ & $0,00 \pm 0,00$ \\
\hline 3 & $300 \mathrm{mg} / \mathrm{mL}$ & $9,08 \pm 0,31$ & $6,79 \pm 0,05$ & $6,82 \pm 0,10$ & $0,00 \pm 0,00$ \\
\hline 4 & $350 \mathrm{mg} / \mathrm{mL}$ & $9,23 \pm 0,37$ & $6,83 \pm 0,01$ & $6,96 \pm 0,13$ & $0,00 \pm 0,00$ \\
\hline 5 & $400 \mathrm{mg} / \mathrm{mL}$ & $9,72 \pm 0,71$ & $6,86 \pm 0,04$ & $7,04 \pm 0,11$ & $6,75 \pm 0,15$ \\
\hline 6 & $450 \mathrm{mg} / \mathrm{mL}$ & $\mathbf{1 0 , 5 7 \pm 0 , 3 5}$ & $6,91 \pm 0,03$ & $7,33 \pm 0,21$ & $7,16 \pm 0,21$ \\
\hline $\mathrm{P}$ & $\begin{array}{l}\text { Kontrol } \\
\text { (Amoxicillin } \\
\mu \mathrm{g} / \text { disk) }\end{array}$ & \multicolumn{4}{|c|}{$7,60 \pm 0,21$} \\
\hline $\mathrm{N}$ & $\begin{array}{l}\text { Kontrol Negatif } \\
\text { (aquadest steril) }\end{array}$ & \multicolumn{4}{|c|}{0,00} \\
\hline
\end{tabular}

Hasil penelitian yang telah dilakukan diketahui sampel ekstrak dan getah pelepah serta bonggol pisang kepok kuning mampu menghambat pertumbuhan kedua bakteri uji. hal ini dibuktikan dengan terbentuknya daerah bebas bakteri (zona bening) di sekitar cakram disk. Hasil pengukuran rata-rata Diameter Daya Hambat (DDH) yang terbentuk dapat dilihat pada Tabel 2 dan Tabel 3. Menurut Davis dan Stout (1971), ketentuan antibakteri adalah sebagai berikut : daerah hambatan $20 \mathrm{~mm}$ atau lebih berarti sangat kuat, daerah hambatan 10-20 mm berarti kuat, 5-10 mm berarti sedang, dan daerah hambatan $5 \mathrm{~mm}$ atau kurang berarti lemah. Hasil penelitian menunjukkan bahwa pada bakteri Pseudomonas aeruginosa yang memberi pengaruh

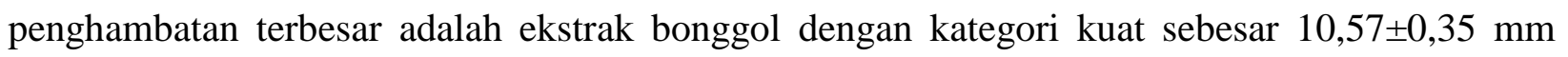


sedangkan pada Klebsiella pneumoniae adalah ekstrak pelepah dengan kategori sedang sebesar $8,62 \pm 0,45 \mathrm{~mm}$ (Tabel 2 dan Tabel 3). Pada penelitian digunakan kontrol positif amoxicillin, yaitu antibiotik turunan penisilin yang memiliki spektrum kerja luas, dengan mekanisme kerja menghambat sintesis dinding sel bakteri. Penggunaan kontrol positif bertujuan untuk melihat gambaran terbunuhnya bakteri uji yang dilihat dari zona hambat (Devi dan Tuty, 2017). Perbedaan aktivitas antibakteri dari kedua sampel disebabkan karena terdapat perbedaan kandungan kimia diantara keduanya, dimana pada sampel ekstak bonggol terdapat senyawa quinin dan saponin yang berperan sebagai antibakteri, sementara pada pelepah didominasi oleh senyawa saponin yang diduga berperan dalam aktivitas antibakteri.

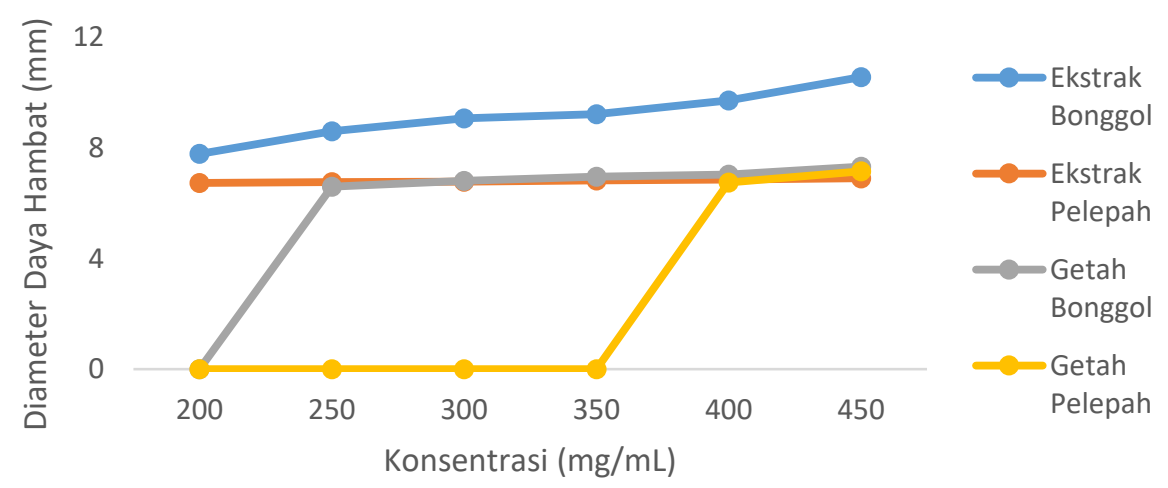

Gambar 3. Grafik uji daya hambat sampel terhadap bakteri Pseudomonas aeruginosa pada ekstrak bonggol, ekstrak pelepah, getah bonggol dan getah pelepah pisang.

Daya hambat yang dihasilkan amoxicillin $25 \mu \mathrm{g} / \mathrm{mL}$ terhadap kedua bakteri uji termasuk dalam kategori sedang, sehingga dapat dikatakan amoxicillin dapat menghambat pertumbuhan kedua bakteri uji. Penggunaan kontrol negatif bertujuan untuk melihat pengaruh aquadest yang digunakan sebagai pengencer sampel, dan diketahui aquadest tidak memiliki aktivitas terhadap bakteri uji sehingga tidak ada pengaruh antara pelarut dengan bakteri uji yang digunakan. Perbedaan aktivitas hambatan bakteri dapat dipengaruhi oleh senyawa aktif, konsentrasi yang tersaring dan adanya bahan organik asing dapat menurunkan keefektifan zat kimia antimikroba (Pelczar dan Chan, 1988). Semakin besar konsentrasi maka semakin besar daya hambat yang dihasilkan, karena semakin besar konsentrasi maka zat aktif yang terkandung semakin besar pula (Sulistyaningrum, 2014). Hasil pengukuran Diameter Daya Hambat (DDH) pada ekstrak dan getah menunjukkan hubungan berbanding lurus dengan kadar konsentrasi yang digunakan. Hubungan antara konsentrasi dan diameter daya hambat dapat dilihat pada Gambar 3 dan Gambar 4. Hasil uji penelitian menunjukkan bahwa sampel ekstrak dan getah pisang kepok kuning memiliki aktivitas 
antibakteri terhadap Pseudomonas aeruginosa dan Klebsiella pneumoniae, namun perlu adanya pengembangan metode yang digunakan untuk menyari kandungan metabolit sekunder dalam sampel agar daya antibakteri yang dihasilkan lebih besar.

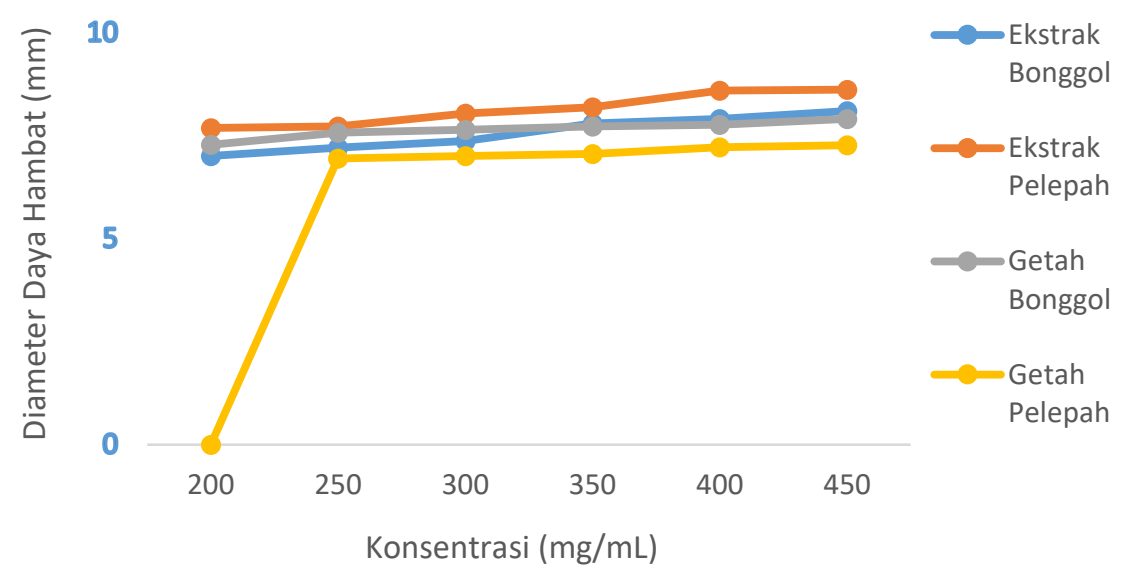

Gambar 4. Grafik uji daya hambat sampel terhadap bakteri Klebsiella pneumoniae pada ekstrak bonggol, ekstrak pelepah, getah bonggol dan getah pelepah pisang.

\section{Kesimpulan}

Ekstrak dan getah pelepah serta bonggol pisang kepok kuning memiliki aktivitas antibakteri terhadap Pseudomonas aeruginosa dan Klebsiella pneumoniae. Senyawa metabolit sekunder yang aktif sebagai agen antibakteri pada keempat sampel adalah saponin, dan pada ekstrak bonggol adalah alkaloid yang dihitung sebagai quinine. Kadar konsentrasi dan diameter daya hambat yang diperoleh memiliki hubungan yang berbanding lurus. Diameter daya hambat paling besar terhadap Pseudomonas aeruginosa dihasilkan oleh ekstrak bonggol dengan kategori kuat $(10,57 \mathrm{~mm} \pm 0,35)$ sedangkan pada Klebsiella pneumoniae dihasilkan oleh ekstrak pelepah dengan kategori sedang $(8,62 \mathrm{~mm} \pm 0,45)$.

\section{Daftar Pustaka}

Aminullah, A. (2005). Masalah Terkini Sepsis Neonatorum. Dalam: Update In Neonatal Infection. Pendidikan Kedokteran Berkelanjutan IKA XLVIII. Jakarta: Departemen Ilmu Kesehatan Anak FKUI-RSCM.

Alen, Y., Fitria, L. A., dan Yori, Y. (2017). Analisis Kromatografi Lapis Tipis (KLT) dan Aktivitas Antihiperurisemia Ekstrak Rebung Schizostachyum brachycladum Kurz (Kurz) pada Mencit Putih Jantan. Jurnal Sains Farmasi dan Klinis, 3(2): 146-152.

Davis, W. W. dan Stout, T. R. (1971). Plate Methods of Microbiological Antibiotic Assay. Applied Microbiology, 22 (4): 666-670.

Devi, S., dan Tuty, M. (2017). Uji Aktivitas Antibakteri Ekstrak Etanol Daun Pacar Kuku (lawsonia inermis Linn) pada Bakteri Pseudomonas aeruginosa. Journal of Current Pharmaceutical Sciences, 1(1). 
Jawetz, E., Melnick, J. L. dan Adelberg, E. A. (2005). Mikrobiologi Kedokteran, Jakarta: Salemba Medika

Lubis, V.A., Yusticia, K. dan Eisabeth, B. (2016a). Identifikasi Bakteri Infeksi Saluran Pernafasan Bawah Non Tuberkulosis (Non TB) dan Pola Resistensinya pada Penderita Diabetes Melitus di RSUP M.Djamil. Jurnal Kesehatan Andalas, 5(3): 692-696.

Lubis, V.A., Katar, Y. dan Bahar, E. (2016b). Identifikasi bakteri infeksi saluran pernafasan bawah non TB dan Pola resistensinya pada penderita Diabetes Melitus. Jurnal kesehatan andalas, 5(3).

Mayasari, E. (2015). Pseudomonas aeruginosa: Karakteristik, Infeksi dan Penanganan. Tersedia dalam: http://Library.usu.ac.id/

Ngajow, M., Jemmy, A. dan Vanda, S. K. (2013). Pengaruh Antibakteri Ekstrak Kulit Batang Matoa (Pometia pinnata) terhadap Bakteri Staphylococcus aureus secara In Vitro. Jurnal MIPA Unsrat Online, 2(2): 128-132.

Ningsih, A. P., Nurmiati, dan Anthoni, A. (2013). Uji Aktivitas Antibakteri Ekstrak Kental Tanaman Pisang Kepok Kuning (Musa paradisiaca Linn.) terhadap Staphylococcus aureus dan Escherichia coli. Jurnal Biologi Universitas Andalas, 207-213

Pelczar, Michael J. ECS. Chan. (1988). Dasar-dasar Mikrobiologi, Jakarta. UI Press.

Rukmono, P. dan Reni, Z. (2013). Uji Kepekaan Antibiotik Terhadap Pseudomonas aeruginosa Penyebab Sepsis Neonatorum. Sari Pediatri, 14(5):332-336.

Sangi, M., Runtuwene, M. R. J., Simbala, H. E. I. dan Makang, V. M. A. (2008). Analisis Fitokimia Tumbuhan Obat Di Kabupaten Minahasa Utara. Chem Prog, 1(1) : 47-53.

Sulistyaningrum, M. (2014). Uji Aktivitas Antibakteri Ekstrak Etanol Daun Kersen (Muntingia calabura L.) Terhadap Bakteri Klebsiella pneumoniae'. Laporan Tugas Akhir. Program Studi D3 Farmasi. Fakultas Matematika dan Ilmu Pengetahuan Alam. Universitas Sebelas Maret. Surakarta.

Tarina, N. T. I., dan Sri, A. F. K. (2017). Deteksi Bakteri Klebsiella pneumonia. Farmaka, 15(2):119-126.

Wibowo, F. X. S. dan Erna, P. (2015). Pemanfaatan Ekstrak Batang Tanaman Pisang (Musa paradisiacal) Sebagai Obat Antiacne dalam Sediaan Gel Antiacne. Jurnal Ilmu Farmasi dan Farmasi Klinik, 12(1) 